\title{
Combined repeated-dose and reproductive/developmental toxicity screening test of 3-amino-5-mercapto-1,2,4-triazole in rats
}

\author{
Junichi Kikuchi', Sunao Aso', Takayuki Koga'1, Katsumi Miyata', Satsuki Hoshuyama', \\ Yuji Kusune', Tomohiko Yoshida², Ryuichi Hasegawa ${ }^{3}$, Shozo Ajimi ${ }^{1}$ \\ and Kotaro Furukawa ${ }^{1}$ \\ ${ }^{1}$ CERI Hita, Chemicals Evaluation and Research Institute, 3-822 Ishii-machi, Hita-shi, Oita 877-0061, Japan \\ ${ }^{2}$ CERI Kurume, 3-2-7 Miyanojin, Kurume-shi, Hukuoka 839-0801, Japan \\ ${ }^{3}$ CERI, Chemical Biotesting Center, 1-4-25 Kouraku, Bunkyo-ku, Tokyo 112-0004, Japan
}

(Received May 14, 2013; Accepted August 12, 2013)

\begin{abstract}
The substance 3-amino-5-mercapto-1,2,4-triazole (AMT, CAS No. 16691-43-3) was daily administered by gavage to $\mathrm{Crl}: \mathrm{CD}$ (SD)IGS rats at doses of 0 (control), 10, 50 , and $250 \mathrm{mg} / \mathrm{kg}$ bw/day. Males (12/group) were treated for a total of 42 days beginning 14 days before mating. Females (12/group) were treated beginning 14 days before mating to day 4 of lactation throughout the mating and gestation periods. No deaths occurred in males but three females died on day 23 of gestation at $250 \mathrm{mg} / \mathrm{kg} / \mathrm{day}$. Only temporary decreases in body weight and food intake were found in both sexes at $250 \mathrm{mg} / \mathrm{kg} / \mathrm{day}$. There were no considerable changes in general appearance, the functional battery tests, biochemical analysis or urinalysis. Anemia was observed in both sexes at $250 \mathrm{mg} / \mathrm{kg} /$ day. The relative weight of thyroid glands was significantly increased in both sexes at $250 \mathrm{mg} / \mathrm{kg} /$ day and hypertrophy of thyroid follicular cells was observed in 50 and $250 \mathrm{mg} / \mathrm{kg}$ /day males and $250 \mathrm{mg} / \mathrm{kg} /$ day females. As this effect on thyroid glands was considered to be the major toxicity, the possible mechanism was discussed comparing with the toxicity of structural similar analogs. Other histopathological changes in males were hypertrophy of centrilobular hepatocytes at $250 \mathrm{mg} / \mathrm{kg} /$ day, and anterior pituitary glands at $50 \mathrm{mg} / \mathrm{kg} /$ day and more. Vacuolization in renal tubular epithelium of females was observed at 50 and $250 \mathrm{mg} / \mathrm{kg} / \mathrm{day}$. For reproduction, the gestation period was prolonged and the delivery index was decreased at $250 \mathrm{mg} / \mathrm{kg} / \mathrm{day}$. The number of pups born and the birth index were also reduced. It was thus concluded that the NOAEL for repeated-dose toxicity was $10 \mathrm{mg} / \mathrm{kg} /$ day based on the thyrotoxicity and renal toxicity, and that the NOAEL for reproductive/developmental toxicity was $50 \mathrm{mg} / \mathrm{kg} /$ day based on the reduced number of offspring, etc.
\end{abstract}

Key words: 3-Amino-5-mercapto-1,2,4-triazole, Repeated-dose toxicity, Reproductive/developmental toxicity, Screening test, Thyrotoxicity

\section{INTRODUCTION}

The substance 3-amino-5-mercapto-1,2,4-triazole (AMT; CAS No. 16691-43-3) is a white or faint yellow powder with a melting point of $300-302^{\circ} \mathrm{C}$ that is soluble in hot water. AMT is enrolled as an existing chemical substance in Japan. There is no toxicity information on AMT. Therefore, the Ministry of Economy, Trade and Industry, Japan, requested the conduct of a combined repeateddose and reproductive/developmental toxicity screening test using rats using the OECD test guideline No. 422
(OECD, 1996).

AMT consists of amitrole (3-amino-1,2,4-triazole; ATZ; CAS No. 61-82-5) with a mercapto group at the 5th position. ATZ is a pesticide and an antithyroid chemical that acts as an inhibitor of thyroid iodide peroxidase both in vitro and in vivo (Alexander, 1959). Wide range of toxicity information on ATZ has already been examined and summarized (EHC, 1994). By ATZ-induced hypothyroidism, excessive hypothalamus-mediated TSH simulation of the thyroid gland causes thyroid hypertrophy and hyperplasia with an increase in the thyroid weight. Con-

Correspondence: Junichi Kikuchi (E-mail: kikuchi-junichi@ceri.jp) 
tinuing stimulation by TSH may eventually lead to thyroid neoplasia. Equivocal results have been reported in different studies on the genotoxic potential of ATZ (EHC, 1994). However, 3-mercapto-1,2,4-triazole (MTZ: CAS No. 3179-31-5) also has a common fundamental structure with AMT, and was demonstrated to have stronger antithyroid activity than ATZ (Takaoka et al., 1994). These 1,2,4-triazole derivatives including 3-nitro-1,2,4triazole (NTZ: CAS No. 24807-55-4) were shown to inhibit thyroid peroxidase in vitro and in vivo in a competitive manner. Structural formulas of AMT and these allied substances were shown in Fig. 1.

A variety of other chemicals are already known to have an antithyroid effect. These chemicals are mainly classified into three groups by their structures, (1) the thioamides (such as thiourea, thiouracil, propylthiouracil, methimazole, carbimazole, and goitrin), (2) aniline derivatives and related compounds (e.g., sulfonamides, paraaminobenzoic acid, paraaminosalicylic acid, and amphenone) and (3) substituted phenols (such as resorcinol, phloroglucinol, and 2,4-dihydroxybenzoic acid) (Capen, 2008). The thioamides generally have more potent activity than other groups. Based on an in vitro analytical study of the inhibition of isolated thyroid peroxidase, two mechanisms by some thioamides were characterized as reversible inhibition in case of ethylenethiourea and $N, N, N^{\prime}, N^{\prime}$-tetramethylthiourea (Doerge and Takazawa, 1990; Freyberger and Ahr, 2006) and irreversible inactivation (mechanismbased, suicide inhibition) of propylthiouracil and 2-mercaptobenzimidazole (Davidson et al., 1978; Doerge, 1986). However, when propylthiouracil was administered to rats, it seemed that only the reversible mechanism is active (Davidson et al., 1978; Taurog and Dorris, 1989). Anyhow, many thioamides are known to induce thyroid neoplasia by long-term exposure to rats (IARC, 2001).

In case of AMT, there are amino and mercapto groups in the single triazole structure, suggesting that each may indicate an independent clear antithyroid action, respectively, and the $3 \mathrm{rd}$ and 5 th positions in the triazole are considered to be equivalent, because the double bonds within the triazole are in a resonance state. Therefore, it is very interesting how the strength of the jointantithyroid actions by amino and mercapto groups in triazole is revealed. On the other hand, ATZ demonstrated no influence on the reproductive parameters in the multi-generation study at a dose of $100 \mathrm{mg} / \mathrm{kg} /$ day which induced hyperplasia of the thyroid in all animals (Gaines et al., 1973). ATZ also demonstrated no treatment-related effect in a teratology study up to $1,000 \mathrm{mg} / \mathrm{kg} /$ day. Therefore, it is presumed that serious reproductive or developmental toxicity is not expected with AMT.
This article reports the results of repeated-dose and reproductive/developmental toxicity of AMT in rats by the OECD Test Guideline No. 422 (OECD, 1996) in compliance with Good Laboratory Practice. As a result, clear hypothyroidism was shown as predicted but the intensity was much lower than the expected. Including with the relevant information, the mechanism of AMT-induced hypothyroidism was discussed that it may be different from that of structural similar analogs such as other triazoles and thioamides.

\section{MATERIALS AND METHODS}

This study was conducted in compliance with OECD guideline No. 422, "Combined Repeated-dose Toxicity Study with the Reproduction/Developmental Toxicity Screening Test" (OECD, 1996) at the Chemicals Evaluation and Research Institute, Japan (CERI, Oita, Japan). All procedures complied with the OECD Principles for Good Laboratory Practice (GLP, November 26, 1997). Animals were treated in compliance with the applicable animal welfare regulations [Declaration of Helsinki (2000) and Guideline for animal experiments at CERI, Hita according to the LABORATORY ANIMAL SCIENCE (1987) by the American Association for Laboratory Animal Science].

\section{Animals and housing conditions}

$\mathrm{Crl}: \mathrm{CD}(\mathrm{SD})$ rats $(\mathrm{SPF})$ consisting of 55 males and 65 females of 8 weeks old were purchased from Hino Breeding Center, Charles River Laboratories Japan, Inc. (Shiga, Japan). Animals were quarantined and acclimatized for 8 days, and then all animals found to be in good health, were allocated to groups using body weight-stratified randomization.

Males were housed in stainless steel, wire-mesh cages. Females were housed in stainless steel, wire-mesh cages until day 14 of pregnancy and after that in polycarbonate cages with wooden chips as bedding (Sunflake; Charles River Japan). Animal rooms were maintained at a stable temperature $\left(22.0-24.5^{\circ} \mathrm{C}\right)$ and relative humidity (44.6$67.5 \%$ ) with 10-15 air changes per hour and an artificial light-dark cycle of 12-12 hr (lights on: 7:00 and lights off: 19:00). Animals were provided a basal diet (MF; Oriental Yeast Co., Tokyo, Japan) and water ad libitum.

\section{Chemicals and dosing}

AMT was purchased from Tokyo Chemical Industries Corporation (Tokyo, Japan; Lot No. FHM01). The AMT used in this study was $100.2 \%$ pure, and stored in a dark and cool place. The stability of the AMT was confirmed 
by infrared spectroscopy (IR) before and after this study. The AMT was suspended in a $5.0 \mathrm{w} / \mathrm{v} \%$ gum arabic solution prepared from gum Arabic (Wako Pure Chemical Corporation, Osaka, Japan) and purified water (Takasugi Pharmaceutical Corporation, Fukuoka, Japan), and administered to the animals by oral gavage. To control rats the vehicle alone was administered. The daily application volume ( $4 \mathrm{ml} / \mathrm{kg}$ body weight) was based on the latest measured body weight.

Before the start of the study, the AMT in the 0.025 and $12.5 \mathrm{w} / \mathrm{v} \%$ formulations was confirmed to be a homogeneous dispersion and stable for 5 days in a dark and cool place using high performance liquid chromatography (HPLC). Dosing solutions were prepared once every three or four days and stored in a dark and cool place. The concentrations of dosing formulations were analyzed at the first preparation by HPLC, and confirmed to be within $100 \pm 10 \%$ of each nominal concentration.

\section{Experimental design}

To 12 males and 12 females AMT was daily administered by gavage at 0 (control), 10,50 and $250 \mathrm{mg} / \mathrm{kg} /$ day. The dose levels were determined based on the results of the following dose-finding study in which three males and three females were given AMT at 0, 25, 250, 500 and $1,000 \mathrm{mg} / \mathrm{kg} /$ day for 14 days. Two males died at 1,000 $\mathrm{mg} / \mathrm{kg} /$ day. Enlargement of the thyroid gland, and hypertrophy and hyperplasia of follicular epithelial cells were observed in males and females at $250 \mathrm{mg} / \mathrm{kg} /$ day and above. Hypertrophy of hepatocytes, centrilobular and prominent nucleoli of centrilobular hepatocytes in the liver, anisonucleosis and prominent nucleoli of the tubular epithelium in of the kidneys were found in both sexes at $500 \mathrm{mg} / \mathrm{kg} /$ day and above. Therefore, the doses were set at $0,10,50$ and $250 \mathrm{mg} / \mathrm{kg} /$ day for the main study.

To males AMT was administered for 42 days beginning from 14 days before mating. On the day after the final administration, 7 of 12 rats in the 0 and $250 \mathrm{mg} / \mathrm{kg} /$ day groups and all in the 10 and $50 \mathrm{mg} / \mathrm{kg} /$ day groups were sacrificed under ether anesthesia and examined. After the administration period, five males in the 0 and $250 \mathrm{mg} /$ $\mathrm{kg}$ /day groups were reared for 14 days without treatment as the recovery group. To females AMT was administered for 42-48 days beginning from 14 days before mating to day 4 of lactation throughout the mating and gestation periods. On the day after the final administration, all females were sacrificed and examined. Five females each in the 0 and $250 \mathrm{mg} / \mathrm{kg}$ /day groups were administered without mating for 42 days and reared for the following 14 days as recovery groups. The first day of dosing was designated as day 1 of administration and the day after the final dose as day 1 of the recovery period.

\section{Observation and examination Repeated-dose toxicity}

During the administration period, animals were observed twice a day for general appearance. During the recovery period, observation was performed once a day. Detailed clinical observations, such as ease of removal from the cage, handling observation and behavior in the arena, were performed once a week for males, and once a week in weeks 1-5 and on the day before necropsy (postpartum day 4) for females. In males, functional observation battery (FOB), such as reflexes, grip strength (with an automated grip strength meter MATYS, Toyo Sangyo, Toyama, Japan) and locomotor activity count (with a rat activity monitoring system, ACTIMO-10, SHINTECHNO, Fukuoka, Japan), were conducted in five rats of each group in week 6 . The details of reflexes examined were as follow: optic, pinna, pain, papillary and air righting reflexes. In females, five rats, delivered on the same or a close day, were examined in each group on the day before necropsy (postnatal day 4). In the 0 and $250 \mathrm{mg} / \mathrm{kg} /$ day recovery groups of males, grip strength and locomotor activity count were examined in recovery week 2 , because statistically significant changes were found in administration week 6.

Body weights were measured on days 1, 3, 7, 14, 21, 28, 35 and 42 in males. Body weight of females were measured on days $1,3,7$ and 14 in the pre-mating period, days $0,7,14,17$ and 20 in the gestation period and days 0 and 4 in the lactation period. In the recovery period, measurement of body weight was performed on days $1,3,7$ and 14 in males and females.

Food consumption was measured on days 1, 3, 7, 14, 21, 28, 35 and 42 in males. Females were measured on days $1,3,7$ and 14 in the pre-mating period, days 0,7 , 14, 17 and 20 in the gestation period and days 0 and 4 in the lactation period. In the recovery period, measurement of food consumption was performed on days 1, 3, 7 and 14 in males and females.

At the termination of the administration and recovery periods, blood samples were collected in five animals per group from the abdominal aorta after overnight fasting under ether anesthesia. Some samples were treated with ethylenediaminetetraacetic acid dipotassium (EDTA$2 \mathrm{~K}$ ) and examined for hematological analysis such as red blood cell count, hemoglobin concentration, hematocrit, mean corpuscular volume (MCV), the mean corpuscular hemoglobin $(\mathrm{MCH})$, mean corpuscular hemoglobin concentration (MCHC), white blood cell count, and platelet count by CELL-DYN3500 (Abbott laboratories, Abbott 
Park, IL, USA). Reticulocyte count and differential white blood cell count were analyzed with ADVIA120 (Siemens, Munich, Germany). Prothrombin time (PT) and activated partial thromboplastin time (APTT) were measured using plasma separated from another part of the sample treated with $3.2 \%$ sodium citrate with $\mathrm{KC}-10 \mathrm{~A}$ (Amelung, Lemgo, Germany). Serum or plasma prepared from the other blood samples were analyzed for aspartate aminotransferase (AST), alanine aminotransferase (ALT), cholinesterase (ChE), total protein, albumin, albumin/globulin ratio, and total bilirubin using 7150 Clinical analyzer (Hitachi High-Tech, Tokyo, Japan). Alkaline phosphatase (ALP), $\gamma$-glutamyltranspeptidase ( $\gamma$-GTP), total cholesterol, triglyceride, glucose, blood urea nitrogen $(\mathrm{BUN})$, creatinine, calcium $(\mathrm{Ca})$, and inorganic phosphorus (IP) were measured by 7170 Clinical analyzer (Hitachi High-Tech). Sodium $(\mathrm{Na})$, potassium $(\mathrm{K})$ and chloride $(\mathrm{Cl})$ were measured using PVA- $\alpha$ (A\&T, Kanagawa, Japan).

At the termination of administration and recovery period, urinalysis was performed in five animals per group. Urine was collected for 15-17 hr in a metabolic cage, and was examined for urine volume, color, turbidity, specific gravity, $\mathrm{pH}$, protein, glucose, occult blood and urinary sediment. Specific gravity and urinary sediment were measured by SPR-N (Atago, Tokyo, Japan) and BH2 (Olympus, Tokyo, Japan), respectively.

All animals were sacrificed by bleeding from the abdominal aorta under ether anesthesia on the day after the final dosing (main group) or after completion of the recovery period (recovery group), and the external surface, all orifices, subcutis, cranial, thoracic, abdominal and pelvic cavities and their components were then examined macroscopically. The brain, pituitary gland, thyroid, thymus, heart, liver, spleen, kidneys, adrenals, testes and epididymides were removed and weighed. The trachea, lungs, stomach, intestines, urinary bladder, prostate, seminal vesicles, ovaries, uterus, vagina, spinal cord, sciatic nerve, bone marrow (femur), axillar lymph nodes and mesenteric lymph nodes were also collected. The testes and epididymides were fixed with modified Davidson fixative, and the other organs and tissues with $10 \%$ neutralized formaldehyde solution. In the 0 and $250 \mathrm{mg} / \mathrm{kg} / \mathrm{day}$ groups, all organs and tissues were sectioned, stained with hematoxylin-eosin and examined histopathologically under a light microscope. The 10 and $50 \mathrm{mg} / \mathrm{kg} /$ day and recovery groups were examined if treatment-related changes were observed in the $250 \mathrm{mg} / \mathrm{kg} /$ day group.

\section{Reproductive/developmental toxicity}

For each female, the estrous cycle was examined by vaginal smear from the first day of administration to the day when successful mating was demonstrated.

In the main group, each female was moved and reared in a cage cohabitated with a male of the same dose group at night until successful copulation occurred or 2 weeks later. The presence of sperm in the vaginal smear and/ or a vaginal plug was considered as evidence of mating, and the day of successful mating was designed as day 0 of gestation. The pregnant females were allowed to deliver spontaneously and nurse their pups. If dams built a nest by 15:00, the day was determined as day 0 of lactation or postnatal day 0 . In addition, the number of corpora lutea on the ovaries and the implantation sites in the uterus were counted at necropsy. The pairing days until copulation, copulation, fertilization, conception and implantation indices, pre/post-implantation loss, delivery dams and delivery indices were calculated in each dose group.

The number of pups born, stillborns, live pups at birth and live pups at the end of observation, sex ratio of pups born and live pups, and external abnormality of live pups were examined on postnatal day 0 . In addition, the general appearance and number of live pups were noted once daily by postnatal day 4 . In each pup, the body weight was measured on postnatal days 0 and 4.

\section{Statistical analysis}

Body weight, food consumption, grip strength, locomotor activity count, hematological and blood chemical parameters, urine volume, specific gravity, organ weights, estrous cycle length, pairing days until copulation, gestation length, number of corpora lutea, implantation sites, pups born, stillborns, live pups at birth and live pups at the end of observation, sex ratios of pups born and live pups on postnatal days 0 and 4 , sex ratio of live pups on postnatal day 4 and pups' weights on postnatal days 0 and 4 were analyzed by the Bartlett's test for homogeneity of variance. If a significant difference $(p<0.05)$ was not found, one-way analysis of variance was performed. If a significant difference was noted $(p<0.05)$ in oneway analysis of variance, the values in the $0 \mathrm{mg} / \mathrm{kg} / \mathrm{day}$ group and each dose group were analyzed by Dunnett's test. If a significant difference $(p<0.05)$ was found in the Bartlett's test, the Kruskal-Wallis test was used. If significant difference was noted $(p<0.05)$, the values were analyzed by the nonparametric Dunnett's test.

The numbers of feces and urine pools were analyzed by the Kruskal-Wallis test. If a significant difference was noted ( $\mathrm{p}<0.05)$, the values were analyzed by nonparametric Dunnett's test.

Abnormal estrous cyclicity ratio, copulation, fertilization, conception and delivery dam indices, and sex ratios 
Combined repeated-dose and reproductive/developmental toxicity of AMT

of live pups at birth and on postnatal days 0 and 4 were analyzed by Fisher's exact test.

The implantation index, pre/post-implantation loss, delivery index, external abnormality pups ratio, delivery index and viability indices on postnatal days 0 and 4 were examined by the Kruskal-Wallis test.

\section{RESULTS}

\section{General appearance and functional observations}

No deaths occurred in males. White turbid urine and salivation right after administration were observed in all males in the $250 \mathrm{mg} / \mathrm{kg}$ /day group. Soft stools were also found in 8 of 12 males in the $250 \mathrm{mg} / \mathrm{kg}$ /day group. Three females in the $250 \mathrm{mg} / \mathrm{kg} /$ day group died during late gestation, and white turbid urine and salivation were transiently observed in the $250 \mathrm{mg} / \mathrm{kg} /$ day group. No other clinical findings in both sexes were noted during the administration and recovery periods on daily clinical observations and detailed observations. For the functional observations, there were no treatment-related changes in all groups of both sexes (data not shown).

\section{Body weight and food consumption}

The body weights of males and females in the $250 \mathrm{mg} / \mathrm{kg} /$ day group were lower than those of the controls as shown in Figs. 2 and 3. But a statistically signifi- cantly low value was only found at 35 days after the start of administration, and there were no statistically significant differences between the control and each experimental group in both sexes including the recovery groups.

Statistically significant low change in food consumption was found in males in the $250 \mathrm{mg} / \mathrm{kg}$ /day group on administration days 14 and 28, in females in the $50 \mathrm{mg} /$ $\mathrm{kg} /$ day group on administration days 7 and in the 250 $\mathrm{mg} / \mathrm{kg}$ /day group on administration days 7 and 14 . There were no statistically significant changes in food consumption in other periods and/or other group (data not shown).

\section{Hematological examination}

Hematological analysis data shows that AMT obviously induces anemia in both sexes (Table 1). In males and females, red blood cell count, hemoglobin concentration and hematocrit value were decreased by $10-20 \%$ and the MCV and MCHC were increased by $10 \%$ at 250 $\mathrm{mg} / \mathrm{kg} /$ day compared to the controls. These changes were not found in the recovery groups. Other significant changes were not considered to be a treatment-related effect because they were within the range of background data and/or not dose-related.

\section{Blood chemical examination}

Among 19 parameters examined at the end of administration and in the recovery periods, only five points in

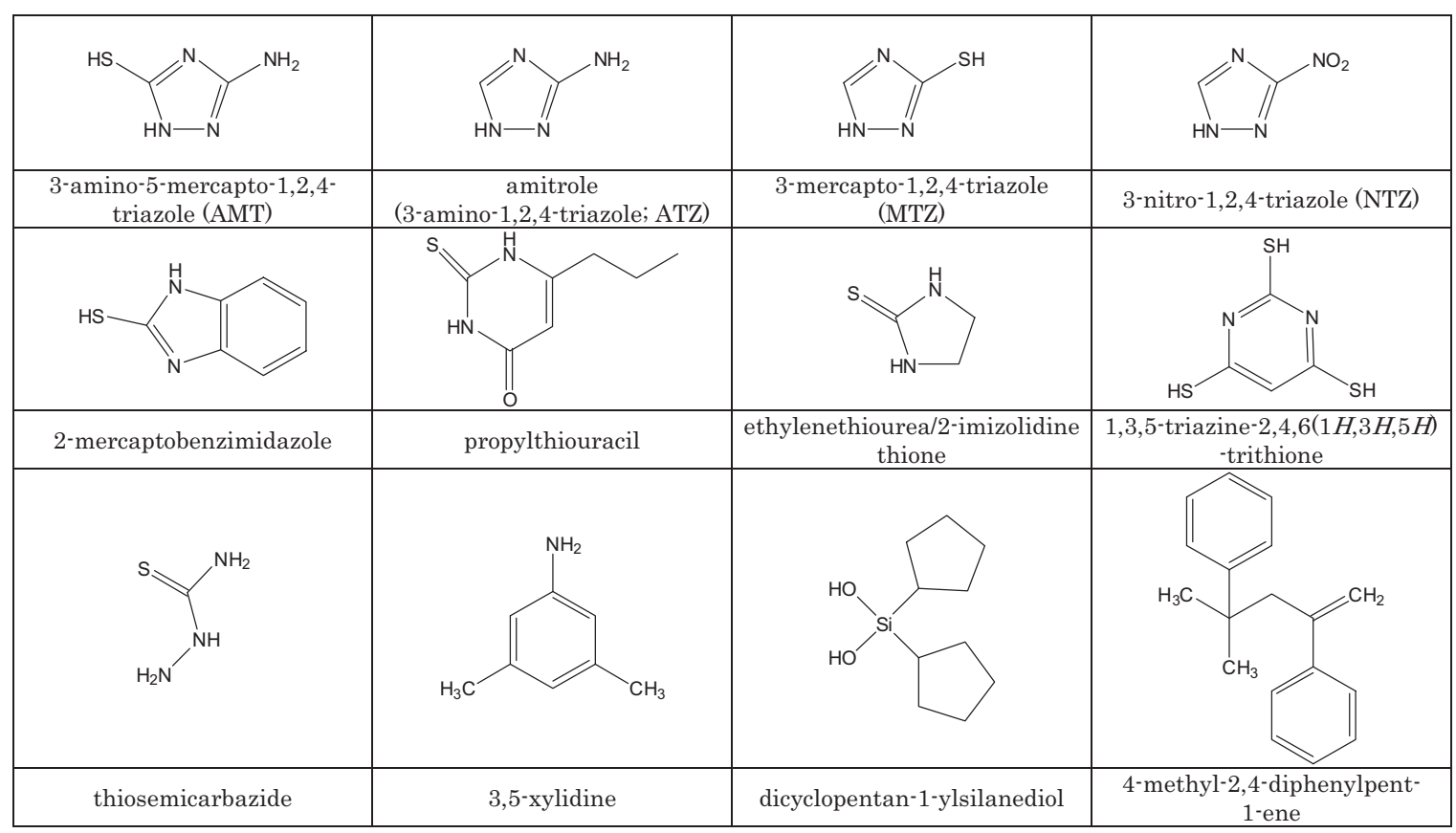

Fig. 1. Structural formulas of 3-amino-5-mercapto-1,2,4-triazol and allied or reference substances. 


\section{J. Kikuchi et al.}

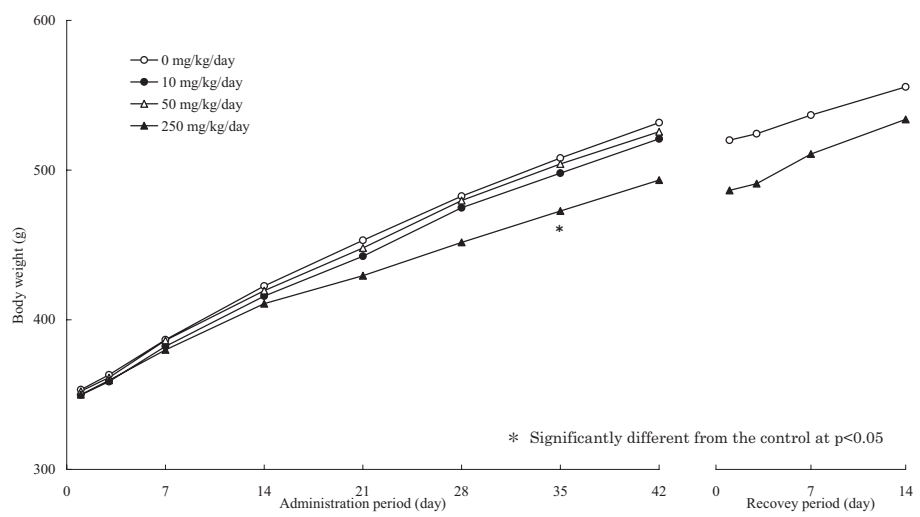

Fig. 2. Body weights of male rats treated orally with 3-amino-5-mercapto-1,2,4-triazole.
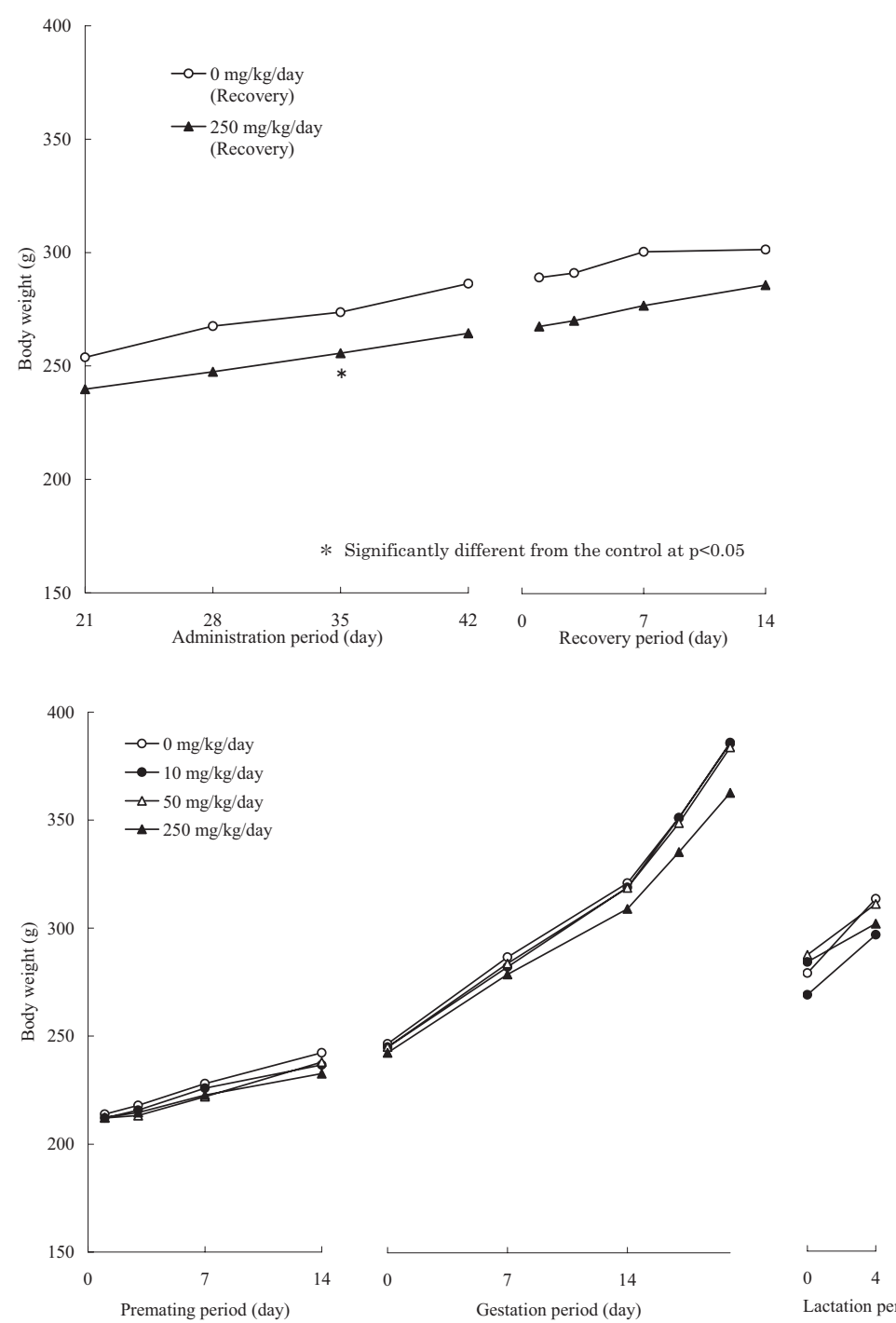

Fig. 3. Body weights of female rats treated orally with 3-amino-5-mercapto-1,2,4-triazole. 
Combined repeated-dose and reproductive/developmental toxicity of AMT

males or females were statistically significantly different from the controls. However, these were not considered to be due to an adverse effect of AMT because all of them were within the range of the background data and/ or not dose-related, except the increase in total cholesterol in $250 \mathrm{mg} / \mathrm{kg} /$ day males $(70 \%$ of the control) (date not shown).

\section{Urinalysis}

There were no treatment-related changes in all groups of both sexes (data not shown).

\section{Organ weights}

In males, there were no critical changes in the absolute organ weights but the relative organ weights of the liver and thyroid glands in the $250 \mathrm{mg} / \mathrm{kg}$ /day group were statistically significantly increased by $27 \%$ and $30 \%$ of the control, respectively, in the main study (Tables 2 and 3). These changes recovered to the normal level after the recovery period. In females, the absolute and relative organ weights of the thyroid glands in the $250 \mathrm{mg} / \mathrm{kg} /$ day group were statistically significantly increased while no statistically significant changes in the absolute and relative organ weights of the liver were noted. Additionally, the relative kidney weight in $250 \mathrm{mg} / \mathrm{kg} /$ day females was increased by $17 \%$ (not statistically significant) in the main study and increased statistically significantly by $10 \%$ after the recovery period, compared to the controls.

\section{Histopathological findings}

Full histopathological examination was conducted and the results in specified organs that seemed to be due to the test substance are summarized in Table 4.

In males, follicular cell hypertrophy of the thyroid glands was observed in $60 \%$ of animals at $50 \mathrm{mg} / \mathrm{kg} /$ day and vacuolization, hypertrophy and decreased eosinophilic granules of the cells in the anterior pituitary glands were observed in all animals at $250 \mathrm{mg} / \mathrm{kg} /$ day. Hypertrophy of centrilobular hepatocytes was also noted in all animals at $250 \mathrm{mg} / \mathrm{kg} /$ day. In kidneys at $250 \mathrm{mg} / \mathrm{kg} /$ day, increases in the eosinophilic bodies and hyaline droplets were found and these were identified as $\alpha_{2 u}$-globulin evidenced by specific antibody staining. Ultimobranchial rests of the thyroid gland and solitary cysts in the medulla and a subcapsular solitary cyst of the kidney were incidental because they were found spontaneously and at a low incidence.

In females, follicular cell hypertrophy of the thyroid glands was observed at $250 \mathrm{mg} / \mathrm{kg} /$ day without any changes in the anterior pituitary gland and liver. In kidneys, vacuolization of the tubular epithelium with or without regenerative epithelium was found in one of five females at $10 \mathrm{mg} / \mathrm{kg} /$ day, four of six females at $50 \mathrm{mg} / \mathrm{kg} /$ day and three of twelve females at $250 \mathrm{mg} / \mathrm{kg} /$ day. The renal changes in one female at $10 \mathrm{mg} / \mathrm{kg} / \mathrm{day}$ were judged to have occurred due to incidental bad health, and not to be caused by the administration of AMT, because extremely low food intake during the lactation period, emaciation, atrophy of the thymus and hypertrophy of the squamous epithelium in the forestomach, etc. observed as bad health markers were not found in females in the higher dose groups. An increase in extramedullary hematopoiesis in the liver and spleen was found in one and three of twelve animals, respectively, at $250 \mathrm{mg} /$ $\mathrm{kg} /$ day. In three females found dead on day 23 of gestation, the main changes were perforation or necrosis of the fundic mucosa in the forestomach or glandular stomach, adrenal cortex hypertrophy, and vacuolization of the tubular epithelium with regenerative epithelium.

After the recovery period, there were no treatment-related changes in any organs at $250 \mathrm{mg} / \mathrm{kg} /$ day.

\section{Reproductive/Developmental toxicity}

There were no statistically significant changes in the mean estrous cycle length or cyclicity in any groups (data not shown). Reproductive/developmental parameters are described in Table 5. The number of mated pairs, copulated pairs and pregnant females, including the related indices were not affected by AMT administration. Three pregnant females at $250 \mathrm{mg} / \mathrm{kg}$ /day died on gestation day 23 without delivery and one pregnant female at $250 \mathrm{mg} /$ $\mathrm{kg}$ /day was sacrificed because of no delivery until gestation day 25. Therefore, the post-implantation loss ([(Number of implantation sites - Number of live pups at birth) /Number of implantation sites] $\times 100$ ) at $250 \mathrm{mg} /$ $\mathrm{kg}$ /day was dramatically increased as almost 5-fold the control, although it is not statistically significant. Two females at $250 \mathrm{mg} / \mathrm{kg} /$ day delivered only one and two pups, respectively, and all pups died in postpartum day 0 . Entire litter was loss during postpartum day 1 to 3 was observed in each one of the control, 50 and $250 \mathrm{mg} / \mathrm{kg} /$ day females due to abandonment of pups. Two females at $50 \mathrm{mg} / \mathrm{kg} /$ day were infertile, but no histopathological abnormalities were found in any reproductive organs. In the $250 \mathrm{mg} / \mathrm{kg} /$ day group, the gestation length was statistically significantly extended, but no statistically significant changes were found in the number of corpora lutea or implantation sites. On the other hand, the delivery dam index (number of pups born/number of implantation sites) and the number of pups born were statistically significantly decreased by $36 \%$ and $46 \%$, respectively, of the control. Due to this decreased number of pups born, 
J. Kikuchi et al.

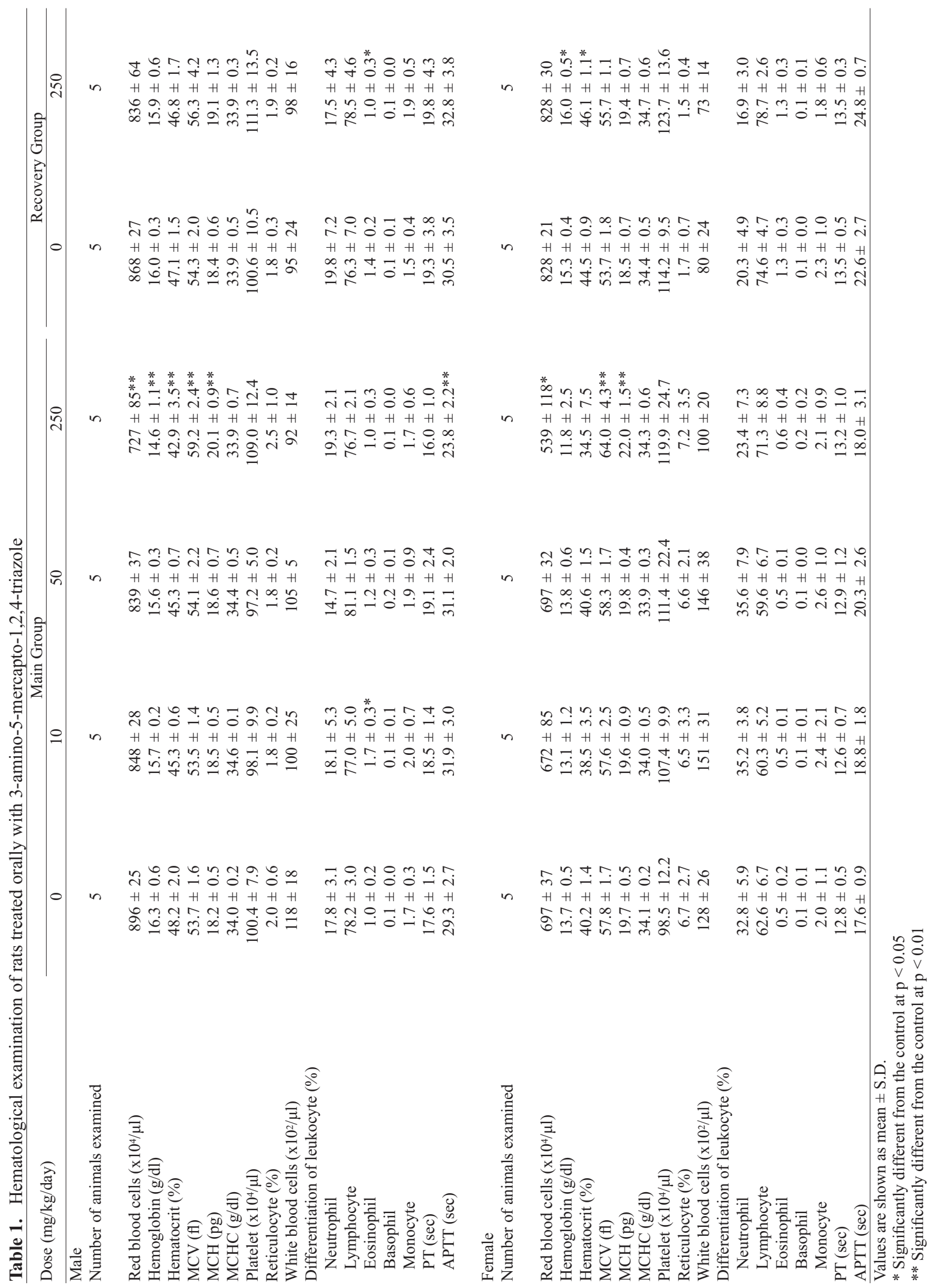

Vol. 38 No. 5 
Combined repeated-dose and reproductive/developmental toxicity of AMT

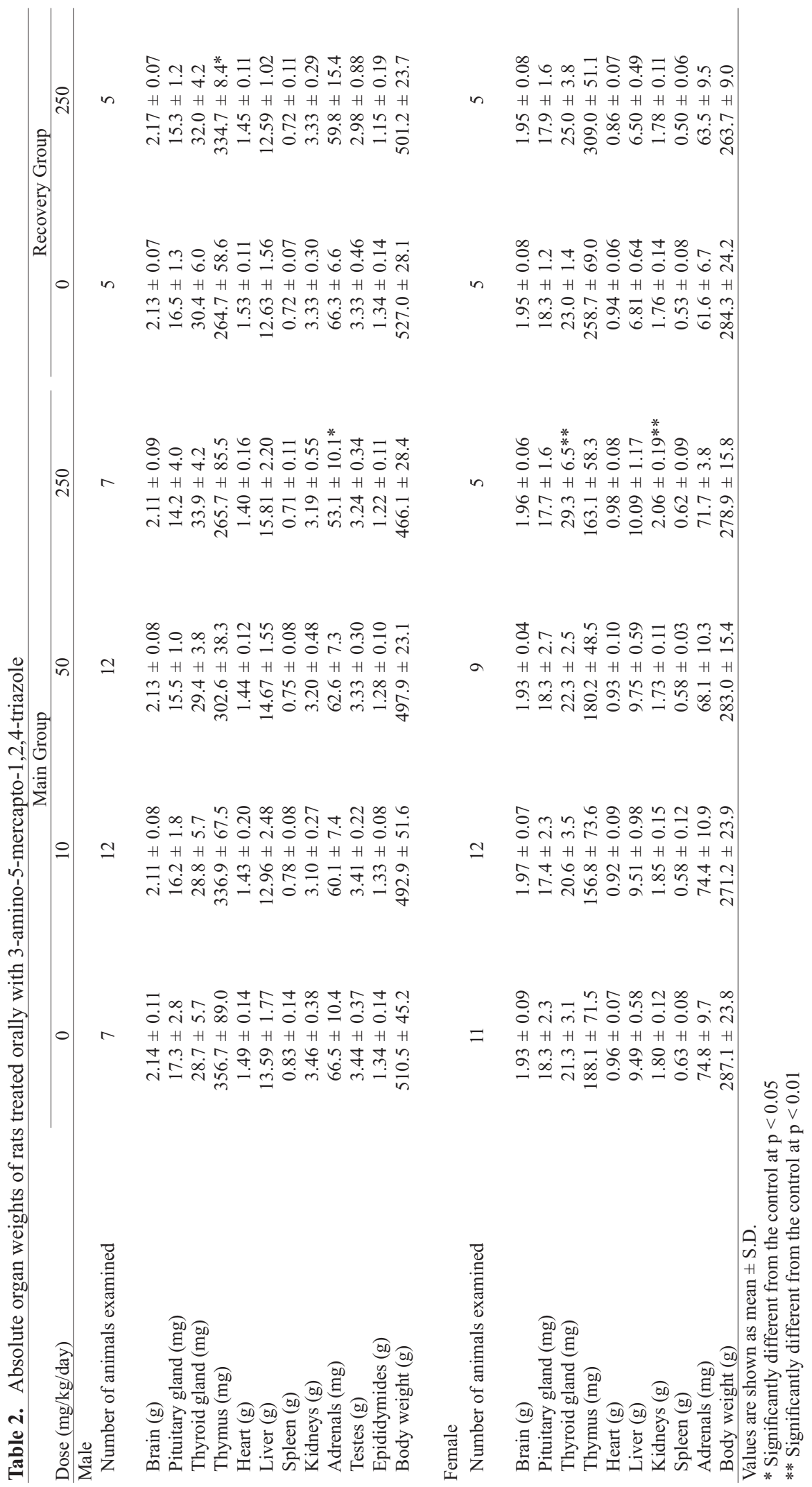


J. Kikuchi et al.

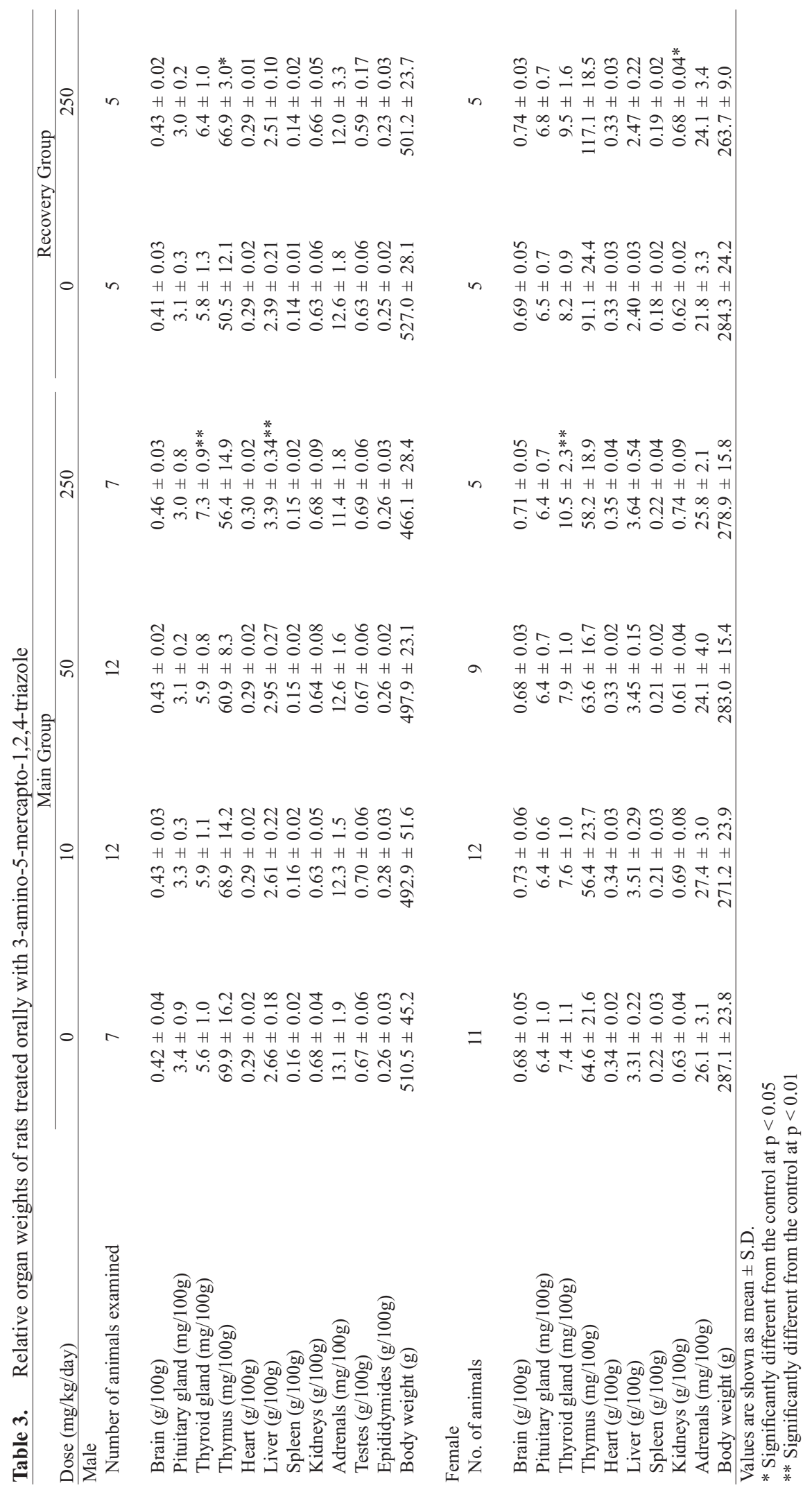

Vol. 38 No. 5 
Combined repeated-dose and reproductive/developmental toxicity of AMT

Table 4. Histopathological findings of rats treated orally with 3-amino-5-mercapto-1,2,4-triazole

\begin{tabular}{|c|c|c|c|c|c|c|c|}
\hline \multirow[b]{2}{*}{ Dose (mg/kg/day) } & \multicolumn{5}{|c|}{ Main Group } & \multicolumn{2}{|c|}{ Recovery Group } \\
\hline & Grade & 0 & 10 & 50 & 250 & 0 & 250 \\
\hline \multicolumn{8}{|l|}{ Male } \\
\hline Number of animals examined & & 5 & 5 & 5 & 5 & 5 & 5 \\
\hline \multicolumn{8}{|l|}{ Pituitary gland } \\
\hline No abnormalities detected & & 5 & 5 & 2 & 0 & 5 & 5 \\
\hline Decreased eosinophilic granules of anterior pituitary cells & + & 0 & 0 & 0 & 1 & 0 & 0 \\
\hline Hypertrophy of anterior pituitary cells & + & 0 & 0 & 1 & 2 & 0 & 0 \\
\hline \multirow[t]{2}{*}{ Vacuolization of anterior pituitary cells } & + & 0 & 0 & 2 & 4 & 0 & 0 \\
\hline & ++ & 0 & 0 & 0 & 1 & 0 & 0 \\
\hline \multicolumn{8}{|l|}{ Thyroid gland } \\
\hline No abnormalities detected & & 4 & 5 & 2 & 0 & 5 & 5 \\
\hline \multirow[t]{2}{*}{ Follicular cell hypertrophy } & \pm & 0 & 0 & 3 & 1 & 0 & 0 \\
\hline & + & 0 & 0 & 0 & 4 & 0 & 0 \\
\hline Ultimobranchial rest & + & 1 & 0 & 0 & 0 & 0 & 0 \\
\hline \multicolumn{8}{|l|}{ Liver } \\
\hline No abnormalities detected & & 5 & 5 & 5 & 0 & 5 & 5 \\
\hline \multirow[t]{2}{*}{ Hypertrophy of centrilobular hepatocytes } & + & 0 & 0 & 0 & 3 & 0 & 0 \\
\hline & ++ & 0 & 0 & 0 & 2 & 0 & 0 \\
\hline Prominent nucleoli of hepatocytes & + & 0 & 0 & 0 & 1 & 0 & 0 \\
\hline \multicolumn{8}{|l|}{ Spleen } \\
\hline No abnormalities detected & & 4 & - & - & 5 & - & - \\
\hline Capsulitis & ++ & 1 & - & - & 0 & - & - \\
\hline \multicolumn{8}{|l|}{ Kidneys } \\
\hline No abnormalities detected & & 5 & 4 & 4 & 2 & 4 & 4 \\
\hline Cyst formation in medulla & + & 0 & 0 & 0 & 0 & 0 & 1 \\
\hline \multirow[t]{2}{*}{ Increased eosinophilic bodies } & \pm & 0 & 0 & 0 & 0 & 0 & 1 \\
\hline & + & 0 & 0 & 0 & 3 & 0 & 0 \\
\hline Increased hyaline droplets & + & 0 & 0 & 0 & 2 & 0 & 0 \\
\hline Solitary cyst in medulla & + & 0 & 0 & 0 & 1 & 1 & 0 \\
\hline Subcapsular solitary cyst & + & 0 & 1 & 1 & 0 & 0 & 0 \\
\hline \multicolumn{8}{|l|}{ Female } \\
\hline Number of animals examined & & 5 & 5 & 5 & 5 & 5 & 5 \\
\hline \multicolumn{8}{|l|}{ Pituitary gland } \\
\hline No abnormalities detected & & 5 & - & - & 5 & - & - \\
\hline Number of animals examined & & 5 & 5 & 5 & 7a) & 5 & 5 \\
\hline \multicolumn{8}{|l|}{ Thyroid gland } \\
\hline No abnormalities detected & & 5 & 4 & 4 & 2 & 5 & 5 \\
\hline Ectopic thymic tissue & + & 0 & 1 & 0 & 0 & 0 & 0 \\
\hline Follicular cell hypertrophy & + & 0 & 0 & 0 & 5 & 0 & 0 \\
\hline Ultimobranchial rest & + & 0 & 0 & 1 & 0 & 0 & 0 \\
\hline Number of animals examined & & $6^{\text {a) }}$ & 5 & $6^{\text {a) }}$ & $12^{\mathrm{b})}$ & 5 & 5 \\
\hline Liver & & & & & & & \\
\hline No abnormalities detected & & 6 & 5 & 6 & 10 & 5 & 5 \\
\hline Focal necrosis of hepatocytes & ++ & 0 & 0 & 0 & 1 & 0 & 0 \\
\hline Increased extramedullary hematopoiesis & + & 0 & 0 & 0 & 1 & 0 & 0 \\
\hline Spleen & & & & & & & \\
\hline Autolysis & & 0 & 0 & 0 & 1 & 0 & 0 \\
\hline No abnormalities detected & & 6 & 5 & 6 & 7 & 5 & 5 \\
\hline Atrophy & + & 0 & 0 & 0 & 1 & 0 & 0 \\
\hline Increased extramedullary hematopoiesis & + & 0 & 0 & 0 & 2 & 0 & 0 \\
\hline & ++ & 0 & 0 & 0 & 1 & 0 & 0 \\
\hline Kidneys & & & & & & & \\
\hline No abnormalities detected & & 6 & 4 & 2 & 9 & 5 & 5 \\
\hline Hyaline cast & + & 0 & 0 & 0 & 1 & 0 & 0 \\
\hline Vacuolization of tubular epithelium & + & 0 & 0 & 1 & 0 & 0 & 0 \\
\hline & ++ & 0 & 0 & 1 & 0 & 0 & 0 \\
\hline Vacuolization of tubular epithelium with regenerative epithelium & + & 0 & 1 & 2 & 3 & 0 & 0 \\
\hline
\end{tabular}

a): contain a dam of all her pups died after birth.

b): contain a dam of all her pups died after birth, dams all her embryos after implantation and dead animals during gestation.

-: not examined.

\pm : very slight, + : slight, ++ : moderate. 
J. Kikuchi et al.

Table 5. Postnatal course of rat litters whose parents treated orally with 3-amino-5-mercapto-1,2,4-triazole

\begin{tabular}{|c|c|c|c|c|}
\hline Dose $(\mathrm{mg} / \mathrm{kg} /$ day $)$ & 0 & 10 & 50 & 250 \\
\hline Number of mated pairs & 12 & 12 & 12 & 12 \\
\hline Number of copulated pairs & 12 & 12 & 12 & 12 \\
\hline Number of pregnant females & 12 & 12 & 10 & 12 \\
\hline Copulation index ${ }^{a)}(\%)$ & 100.0 & 100.0 & 100.0 & 100.0 \\
\hline Fertilization index ${ }^{\mathrm{b})}(\%)$ & 100.0 & 100.0 & 83.3 & 100.0 \\
\hline Conception index $(\%)$ & 100.0 & 100.0 & 83.3 & 100.0 \\
\hline Pairing days until copulation (Mean \pm S.D.) & $1.9 \pm 1.6$ & $2.6 \pm 1.6$ & $2.4 \pm 1.3$ & $2.0 \pm 1.3$ \\
\hline Number of pregnants & 12 & 12 & 10 & 12 \\
\hline Gestation length (Mean \pm S.D., day) & $22.3 \pm 0.5$ & $22.2 \pm 0.4$ & $22.0 \pm 0.0$ & $23.3 \pm 0.5^{* *}$ \\
\hline Number of corpora lutea (Mean \pm S.D.) & $15.6 \pm 2.1$ & $15.8 \pm 1.8$ & $13.8 \pm 2.7$ & $14.8 \pm 3.9$ \\
\hline Number of implantation sites (Mean \pm S.D.) & $14.7 \pm 2.5$ & $15.2 \pm 1.9$ & $13.3 \pm 2.7$ & $14.1 \pm 4.2$ \\
\hline Implantation index d) $($ Mean \pm S.D., \%) & $93.7 \pm 8.1$ & $95.7 \pm 6.4$ & $96.3 \pm 5.4$ & $90.9 \pm 18.7$ \\
\hline Preimplantation loss e) $($ Mean \pm S.D., \%) & $6.4 \pm 8.1$ & $4.3 \pm 6.4$ & $3.8 \pm 5.4$ & $9.1 \pm 18.7$ \\
\hline Postimplantation loss ${ }^{\text {f) }}($ Mean \pm S.D., \%) & $9.9 \pm 8.8$ & $10.8 \pm 11.8$ & $10.7 \pm 10.5$ & $46.7 \pm 41.2$ \\
\hline Delivery dam index ${ }^{g}(\%)$ & $100.0(12 / 12)$ & $100.0(12 / 12)$ & $100.0(10 / 10)$ & $66.7(8 / 12)$ \\
\hline Delivery index ${ }^{\text {h) }}($ Mean \pm S.D., \%) & $92.2 \pm 9.0$ & $95.3 \pm 6.2$ & $93.6 \pm 6.3$ & $59.3 \pm 39.0^{*}$ \\
\hline \multicolumn{5}{|l|}{ Number of dams with live newborns } \\
\hline on postpartum day 0 & 12 & 12 & 10 & 6 \\
\hline on postpartum day 4 & 11 & 12 & 9 & 5 \\
\hline \multicolumn{5}{|l|}{ Postnatal day 0} \\
\hline Number of pups born (Mean \pm S.D.) & $13.6 \pm 2.7$ & $14.5 \pm 2.2$ & $12.4 \pm 2.5$ & $7.3 \pm 5.9 * *$ \\
\hline Number of stillborns (Mean \pm S.D.) & $0.3 \pm 0.9$ & $0.9 \pm 1.8$ & $0.6 \pm 1.1$ & $0.9 \pm 2.0$ \\
\hline Number of live pups at birth (Mean \pm S.D.) & $13.3 \pm 2.6$ & $13.6 \pm 2.7$ & $11.8 \pm 2.5$ & $6.4 \pm 5.9^{* *}$ \\
\hline Birth index ${ }^{\text {i) }}($ Mean \pm S.D., \%) & $90.1 \pm 8.8$ & $89.2 \pm 11.8$ & $89.3 \pm 10.5$ & $53.4 \pm 41.1$ \\
\hline Live birth index ${ }^{\text {j) }}($ Mean \pm S.D., \%) & $97.9 \pm 5.6$ & $93.8 \pm 11.9$ & $95.3 \pm 8.5$ & $84.9 \pm 28.2$ \\
\hline Sex ratio of pups born $\left.{ }^{k}\right)$ & $81 / 163$ & $95 / 174$ & $64 / 124$ & $29 / 66$ \\
\hline$($ Mean \pm S.D. $)$ & $0.49 \pm 0.09$ & $0.55 \pm 0.15$ & $0.51 \pm 0.10$ & $0.64 \pm 0.31$ \\
\hline Sex ratio of live pups ${ }^{1)}$ & $81 / 158$ & $89 / 162$ & $62 / 118$ & $30 / 55$ \\
\hline$($ Mean \pm S.D. $)$ & $0.51 \pm 0.09$ & $0.54 \pm 0.18$ & $0.52 \pm 0.10$ & $0.63 \pm 0.26$ \\
\hline Number of live pups at birth with external anomalies & $0 / 159$ & $0 / 163$ & $0 / 118$ & $0 / 58$ \\
\hline External anomaly index ${ }^{\mathrm{m})}($ Mean \pm S.D., $\%)$ & $0.0 \pm 0.0$ & $0.0 \pm 0.0$ & $0.0 \pm 0.0$ & $0.0 \pm 0.0$ \\
\hline \multicolumn{5}{|l|}{ Pups weight (Mean \pm S.D., g) } \\
\hline Male & $6.36 \pm 0.85$ & $6.13 \pm 0.40$ & $6.49 \pm 0.87$ & $6.49 \pm 0.79$ \\
\hline Female & $6.02 \pm 0.72$ & $5.85 \pm 0.28$ & $6.21 \pm 0.92$ & $6.21 \pm 0.50$ \\
\hline \multicolumn{5}{|l|}{ Postnatal day 4} \\
\hline Number of live pups (Mean \pm S.D.) & $12.1 \pm 4.6$ & $13.4 \pm 2.7$ & $10.3 \pm 4.2$ & $6.3 \pm 6.5$ \\
\hline Viability index ${ }^{\mathrm{n}}($ Mean \pm S.D., \%) & $91.0 \pm 28.8$ & $98.8 \pm 2.8$ & $88.8 \pm 31.4$ & $61.5 \pm 51.0$ \\
\hline Sex ratio of live pups ${ }^{\circ)}$ & $73 / 145$ & $88 / 161$ & $53 / 103$ & $27 / 50$ \\
\hline$($ Mean \pm S.D.) & $0.50 \pm 0.09$ & $0.54 \pm 0.18$ & $0.51 \pm 0.10$ & $0.64 \pm 0.29$ \\
\hline \multicolumn{5}{|l|}{ Pups weight (Mean \pm S.D., g) } \\
\hline Male & $10.53 \pm 2.25$ & $9.42 \pm 1.65$ & $11.05 \pm 1.98$ & $10.13 \pm 2.12$ \\
\hline Female & $10.04 \pm 1.88$ & $9.19 \pm 1.57$ & $10.60 \pm 2.05$ & $9.92 \pm 1.36$ \\
\hline
\end{tabular}

a): (Number of copulated pairs /Number of mated pairs) $\times 100$

b): (Number of impregnated males /Number of males in copulated pairs $) \times 100$.

c): (Number of pregnant females /Number of females in copulated pairs $) \times 100$

d): (Number of implantation sites /Number of corpora lutea) $\times 100$.

e): [(Number of corpora lutea - Number of implantation sites) /Number of corpora lutea $] \times 100$.

f): [(Number of implantation sites - Number of live pups at birth) /Number of implantation sites] $\times 100$.

g): (Number of pregnant females with live pups at birth /Number of pregnant females) $\times 100$.

h): (Number of pups born /Number of implantation sites) $\times 100$.

i): (Number of live pups at birth /Number of implantation sites) $\times 100$.

j): (Number of live pups at birth /Number of pups born) $\times 100$.

k): Number of males born /Number of pups born.

1): Number of live males on postnatal day 0 /Number of live pups on postnatal day 0 .

$\mathrm{m})$ : (Number of live pups at birth with external anomalies/Number of live pups at birth) $\times 100$

n): (Number of live pups on postnatal day $4 /$ Number of live pups at birth) $\times 100$.

o): Number of live males on postnatal day 4 /Number of live pups on postnatal day 4 .

*: Significantly different from the control at $\mathrm{P}<0.05$.

**: Significantly different from the control at $\mathrm{P}<0.01$. 
Combined repeated-dose and reproductive/developmental toxicity of AMT

the number of live pups at birth and the birth index were also statistically significantly decreased by $52 \%$ and $40 \%$, respectively, of the control. However, there were no statistically significant changes in the sex ratio and pups' weights on postpartum day 0 and postpartum day 4 , and no external anomalies of the pups.

\section{DISCUSSION}

The most expected effect of AMT was considered to be toxicity of the thyroid glands, because two antithyroidal structures are present within a single molecule, the triazole derivative. In fact, the relative thyroid weight was statistically significantly increased in both sexes at $250 \mathrm{mg} / \mathrm{kg} /$ day and hypertrophy of thyroid follicular cells was observed in males at 50 and $250 \mathrm{mg} / \mathrm{kg} /$ day and in females at $250 \mathrm{mg} / \mathrm{kg}$ /day. Hypertrophy or vacuolization of the anterior pituitary glands was also found in males at $250 \mathrm{mg} / \mathrm{kg} /$ day. However, we recognized that AMT at a dose of $250 \mathrm{mg} / \mathrm{kg} /$ day, even for longer than 42 days of administration, has an unexpectedly small effect on the relative weight of the thyroid gland such as 1.3 - and 1.4-fold that of males and females, respectively, in the control group. On the other hand, 2-mercaptobenzimidazole (CAS No. 583-39-1), known as a strong antithyroid chemical, induced a 12.6- and 11.2-fold increase in the relative thyroid weight of males and females, respectively, at $50 \mathrm{mg} / \mathrm{kg} /$ day in the 28 -day repeated-dose oral toxicity study compared to the control (Kawasaki et al., 1998). Propylthiouracil (CAS No. 51-52-5) induced a 2.8fold increase in the relative thyroid weight of males at the very low dose of $1.0 \mathrm{mg} / \mathrm{kg} /$ day in the 28 -day oral study (Yamasaki et al., 2002). A weak thyrotoxic substance, ethylenethiourea/2-imizolidinethione (CAS No. 96-45-7) even induced 1.9- and 1.6-fold increases in the relative thyroid weight in males and females, respectively, at 30 $\mathrm{mg} / \mathrm{kg} /$ day in the 28 days oral study (MHLW, 2004) compared to the control. ATZ (2.8-fold increase in the relative thyroid thyroid weight in males at $126 \mathrm{mg} / \mathrm{kg} / \mathrm{day}$ for 7 days compared to the control) and MTZ (2.7-fold increase in the relative thyroid weight of males at $152 \mathrm{mg} /$ $\mathrm{kg}$ /day for 7 days) (Takaoka et al., 1994), which are both structural analogs of AMT, showed a remarkably stronger effect than AMT. Structural formulas of these and below reference substances were shown in Fig. 1.

This unexpectedly weak antithyroid effect of AMT may suggest that two active sites in a single molecule must interfere mutually, leading to much lower thyrotoxicity. In fact, there are some cases of chemicals with multiple active sites that did not induce such active toxicity. For example, antithyroid activity was not recognized with 1,3,5-triazine-2,4,6(1H,3H,5H)-trithione (CAS No. 638-16-4) (MHLW, 2007a), which consists of only three thiourea molecules. In the toxicity test report, there is no mention of hypertrophy or relative weight of the thyroid glands, indicating that there were at least no obvious macroscopic changes in the thyroid glands. As another example, thiosemicarbazide (CAS No.79-19-6), which consists of a hydrazine moiety (possible hemolytic anemia) and thiourea (possible thyrotoxicity), induced convulsions, but neither anemia nor thyrotoxicity (Parks et al., 1952).

Another histopathological change caused by AMT was hypertrophy of the centrilobular hepatocytes with an increase in the relative liver weight. In males at the high dose of $250 \mathrm{mg} / \mathrm{kg} /$ day the relative weights of the liver and thyroid were statistically significantly increased by $27 \%$ and $30 \%$, respectively, compared to the control, and in females at the high dose of $250 \mathrm{mg} / \mathrm{kg} /$ day the relative weights of the liver and thyroid were increased by $10 \%$ and $42 \%$, respectively, compared to the control. A similar relationship as that of AMT has been reported for at least three chemicals, namely, 3,5-xylidine (CAS No. 10869-0), dicyclopentan-1-ylsilanediol (CAS No. $211495-$ 85-1) and 4-methyl-2,4-diphenylpent-1-ene (CAS No. 6362-80-7). As for 3,5-xylidine, in males at the high dose of $360 \mathrm{mg} / \mathrm{kg} /$ day the relative weights of the liver and thyroid gland were increased by $29 \%$ and $49 \%$, respectively, compared to the control, and in females at the high dose of $360 \mathrm{mg} / \mathrm{kg} /$ day the relative weights of the liver and thyroid gland were increased by $37 \%$ and $40 \%$, respectively, compared to the control (MHLW, 1997). In case of dicyclopentan-1-ylsilanediol, in males at the high dose of $1000 \mathrm{mg} / \mathrm{kg} /$ day the relative weights of the liver and thyroid gland were increased by $17 \%$ and $20 \%$, respectively, compared to the control, and in females at the high dose of $360 \mathrm{mg} / \mathrm{kg} /$ day the relative weights of the liver and thyroid gland were increased by $34 \%$ and $7 \%$, respectively, compared to the control (MHLW, 2000). For 4-methyl-2,4-diphenylpent-1-ene, in males, at the high dose of $720 \mathrm{mg} / \mathrm{kg} /$ day the relative weights of the liver and thyroid gland were obviously increased by $68 \%$ and $47 \%$, respectively, compared to the control, and in females at the high dose of $720 \mathrm{mg} / \mathrm{kg} /$ day the relative weights of the liver and thyroid gland were increased by $57 \%$ and $32 \%$ compared to the control (MHLW, 2007b). On the other hand, the increases in the relative thyroid weights due to several thioamides are larger than the increases in the relative liver weights, namely, the ratio of the relative thyroid weight to the control versus the relative liver weight to the control ranged from 1.4 to 8.5 for thioamides (Kawasaki et al., 1998; Yamasaki et al., 2002; MHLW, 2004) and from 0.8 to 1.15 for the above-men- 
tioned three chemicals (MHLW, 1997, 2000 and 2007b).

Considering the overall relationship of the relative organ weight changes of the thyroid gland and liver, there is a possibility that hypertrophy of the thyroid follicular cells caused by AMT might have been due to induction of the drug metabolizing enzymes in the liver. The mechanism is generally considered to be that the thyroid gland is stimulated by the increased blood level of thyroid stimulating hormone secreted by the pituitary glands, when the negative feedback effect is reduced due to decreased blood thyroid hormone as a result of metabolic degradation via hepatic induction of UDP-glucuronyl transferase (Capen, 2008). Although there is presently no direct evidence about this chemical, the contribution of induction of the drug-metabolizing enzyme in the liver is more likely the mechanism than the direct action on the thyroid glands in males. This speculation would be reasonably supported by very recent report for the mechanistic consideration of hypothyroidism induced by chemical substances (Yamada et al., 2013). In case of females, there are two possibilities; the drug metabolizing enzyme induction profile in females is different from that in males, or a direct action on the thyroid gland, because the relative weight of the thyroid gland in females was increased much more than the relative weight of the liver as mentioned above.

Histopathological changes of the pituitary glands were clearly observed in males but not females. Because all females conceived and gave birth in this study protocol, this experimental condition may be a reason for no pathological changes of pituitary glands in females. Anyhow, it might be sure that the mechanism of present hypothyroidism will be due to increased degradation of thyroid hormone, followed by high thyroid stimulating hormone secretion from pituitary glands. But the histopathological changes of pituitary glands were much less in rats treated with AMT than 2-mercaptobenzimidazole, one of thioamide derivatives (Kawasaki et al., 1998). In both cases, the hypertrophy of pituitary glands comes from a drop of plasma thyroid hormone level.

Eosinophilic bodies and hyaline droplets were observed in the kidneys of males at $250 \mathrm{mg} / \mathrm{kg} /$ day. These were confirmed to be accumulation of $\alpha_{2 u}$-globulin complex using immunochemical staining, indicating that it is a male rat specific phenomenon (Hamamura et al., 2006).

As another clear effect in repeated-dose toxicity, anemia was observed at $250 \mathrm{mg} / \mathrm{kg} /$ day in both sexes. It seems that the anemia is not based on a hemolytic mechanism, because there are no statistically significant changes of the reticulocyte count ratio, extramedullary hematopoiesis or hemosiderin deposition. Vacuolization of the renal tubular epithelium and regenerative epithelium was found in 1/5, 4/6 and 3/12 females at 10, 50 and $250 \mathrm{mg} /$ $\mathrm{kg} /$ day, respectively. The renal changes in one female at $10 \mathrm{mg} / \mathrm{kg} /$ day were judged not to be caused by AMT. On the other hand, it could not be denied that renal changes in the 50 and $250 \mathrm{mg} / \mathrm{kg} /$ day groups were due to the effect of AMT, even though there was not a clear dose-dependent relationship. However, anemia in both sexes and renal changes in females in this study were at least not considered to be due to thyrotoxicity, because both toxicities were not reported as toxicity due to ATZ or several thioamides. Therefore, the cause of anemia and renal toxicity was unknown.

Three females in the $250 \mathrm{mg} / \mathrm{kg} /$ day group died on the gestation day 23. Those deaths were considered to be caused by AMT due to the height of frequency of occurrence because death in late gestation or during delivery is rarely observed in general. Perforation of the forestomach, necrosis of fundic mucosa of the glandular stomach, hypertrophy of cortex of the adrenals, vacuolization of tubular epithelium with regenerative epithelium of the kidneys, atrophy of the thymus and etc. were found in dead animals. These changes were historically noted in females which died in late gestation and dams whose all litter died after delivery. Therefore, this death was considered to be caused by overlapping the effect of administration and the stress just before delivery.

The reproduction and gestation periods were prolonged and the delivery index decreased at $250 \mathrm{mg} / \mathrm{kg} / \mathrm{day}$. An increase (not statistically significant) of the postimplantation loss was noted at $250 \mathrm{mg} / \mathrm{kg} / \mathrm{day}$, and as this secondary effect, the number of live pups born and the birth index also decreased. In a similar way, a prolonged gestation period and a decrease in the number of live births have been reported when the thyroid function is decreased (Rao and Panda, 1980). At first glance, it may feel that the same happened in this study. However, the decreased thyroid function in the literature was achieved by thyroidectomy, a very severe condition, and the degree of reproductive toxicity is relatively lower than in the present case. Low levels of FSH and LH, and high levels of progesterone and prolactin were also reported as a possible effect of propylthiouracil or thyroidectomy (Hatsuta et al., 2004) on pregnancy. Although both treatment and surgery induced strong thyrotoxicity, the present study showed a very small increase in the relative weight of the thyroid glands. Therefore, the present reproductive toxicity is not considered to be due to decreased thyroid function, and the cause of these changes was unknown though there was a possibility of effects of anemia and renal toxicity.

In summary, the relative weights of the thyroid gland and liver were increased with hypertrophy of thyroid fol- 
Combined repeated-dose and reproductive/developmental toxicity of AMT

licular cells and centrilobular hepatocytes in males and females. Vacuolization in the renal tubular epithelium was observed in females. As for reproduction, the gestation period was prolonged and the delivery index decreased. Based on these findings, it was concluded that $10 \mathrm{mg}$ / $\mathrm{kg}$ /day was the NOAEL based on the thyrotoxicity and renal toxicity for repeated-dose toxicity and the NOAEL was $50 \mathrm{mg} / \mathrm{kg} /$ day due to a reduced number of offspring, etc. for reproductive/developmental toxicity. The mechanism of hypothyroidism was considered that it may come from increased degradation of thyroid hormone by hepatic drug-metabolizing enzyme induction.

\section{ACKNOWLEDGMENTS}

This study was conducted under the Japanese safety inspections of existing chemical substances funded by the Ministry of Economy, Trade and Industry, Japan, and supported by the National Institute of Technology and Evaluation, Japan.

\section{REFERENCES}

Alexander, N.M. (1959): Iodide peroxidase in rat thyroid and salivary glands and its inhibition by anti-thyroid compounds. Fed. Proc., 18, 1530-1533.

Capen, C.C. (2008): 21 Toxic Responses of the Endocrine System. pp.807-879. In: Casarett \& Doull's Toxicology The Basic Science of Poisons $7^{\text {th }}$ edition (Curtis D, Klaassen ed.), McGraw Hill Medical, New York.

Davidson, B., Soodak, M., Neary, J.T., Strout, H.V., Kieffer, J.D., Mover, H. and Maloof, F. (1978): The irreversible inactivation of thyroid peroxidase by methylmercaptoimidazole, thiouracil, and propylthiouracil in vitro and its relationship to in vivo findings. Endocrinology, 103, 871-882.

Doerge, D.R. (1986): Mechanism-based inhibition of lactoperoxidase by thiocarbamide goitrogens. Biochemistry, 25, 4724-4728.

Doerge, D.R. and Takazawa, R.S. (1990): Mechanism of thyroid peroxidase inhibition by ethylenethiourea. Chem. Res. Toxicol., 3, 98-101.

EHC (1994): Environmental Health Criteria No.158 Amitrole, International Programme on Chemical Safety.

Freyberger, A. and Ahr, H.J. (2006): Studies on the goitrogenic mechanism of action of N,N,N',N'-tetramethylthiourea. Toxicology, 217, 169-175.

Gaines, T.B., Kimbrough, R.D. and Linder, R.E. (1973): The toxicity of amitrole in the rat. Toxicol. Appl. Pharmacol., 26, 118-129.

Hamamura, M., Hirose, A., Kamata, E., Katoku, K., Kuwasaki, E., Oshikawa, T., Nakahara, Y., Ema, M. and Hasegawa, R. (2006): Semi-quantitative immunohistochemical analysis of male ratspecific $\alpha_{2 u}$-globulin accumulation for chemical toxicity evaluation. J. Toxicol. Sci., 31, 35-47.

Hatsuta, M., Abe, K., Tamura, K., Ryuno, T., Watanabe, G., Taya, K. and Kogo, H. (2004): Effects of hypothyroidism on the estrous cycle and reproductive hormones in mature female rat. Eur. J. Pharmacol., 486, 343-348.

IARC (2001): IARC monographs on the evaluation of carcinogenic risks to humans, volume 79 Some thyrothropic agents, International Agency for Research on Cancer, Lyon, France.
Kawasaki, Y., Umemura, T., Saito, M., Momma, J., Matsushima, Y., Sekiguchi, H., Matsumoto, M., Sakemi, K., Isama, K., Inoue, T., Kurokawa, Y. and Tsuda, M. (1998): Toxicity study of a rubber antioxidant, 2-mercaptobenzimidazole, by repeated oral administration to rats. J. Toxicol. Sci., 23, 53-68.

MHLW (1997): Twenty-eight-day repeated dose oral toxicity test of 3,5-dimethylaniline in rats. In Toxicity Testing Reports of Environmental Chemicals (Ministry of Health, Labor and Welfare ed.), Vol. 5, pp 391-402, Chemicals Investigation Promoting Council, Japan. http://dra4.nihs.go.jp/mhlw_data/home/pdf/ PDF108-69-0b.pdf (in Japanese).

MHLW (2000): Ninety-day repeated dose oral toxicity test of dicyclopentan-1-ylsilanediol in rats, consigned by Ministry of Health, Labour and Welfare, Japan. http://dra4.nihs.go.jp/mhlw_ data/home/pdf/PDF211495-85-1h.pdf (in Japanese).

MHLW (2004): Twenty-eight-day repeated dose oral toxicity test of 2-imizolidinethione in rats, consigned by Ministry of Health, Labour and Welfare, Japan. http://dra4.nihs.go.jp/mhlw_data/ home/pdf/PDF96-45-7b.pdf (in Japanese).

MHLW (2005): Twenty-eight-day repeated dose oral toxicity test of 2-imidazolidinethione in rats. In Toxicity Testing Reports of Environmental Chemicals (Ministry of Health, Labor and Welfare ed.), Vol. 12, pp 155-170, Chemicals Investigation Promoting Council, Japan.

MHLW (2007a): Final report of combined repeated dose and reproductive/developmental toxicity screening test of trithiocyanuric acid in rats, consigned by Ministry of Health, Labour and Welfare, Japan. http://dra4.nihs.go.jp/mhlw_data/home/pdf/PDF63816-4d.pdf (in Japanese).

MHLW (2007b): Final report of combined repeated dose and reproductive/developmental toxicity screening test of 4-methyl-2,4-diphenylpent-1-ene in rats, consigned by Ministry of Health, Labour and Welfare, Japan. http://dra4.nihs.go.jp/mhlw_data/ home/pdf/PDF6362-80-7d.pdf (in Japanese).

OECD (1996): OECD Guideline For Testing of Chemicals, No. 422, Combined Repeated Dose Toxicity Study with the Reproduction/Developmental Toxicity Screening Test (Original Guideline, adopted 22 March 1996).

Parks, R.E.Jr., Kidder, G.W. and Dewey, V.C. (1952): Thiosemicarbazide toxicity in mice. Proc. Soc. Exp. Biol. Med., 79, 287289.

Rao, P.M. and Panda, J.N. (1980): Effects of hypothyroidism on pregnancy of rats. Indian J. Physiol. Pharmacol., 24, 126-130.

Takaoka, M., Manabe, S., Yamoto, T., Teranishi, M., Matsunuma, N., Masuda, H. and Goto, N. (1994) : Comparative study of goitrogenic actions of 3 -substituted 1,2,4-triazoles in rats. J. Vet. Med. Sci., 56, 341-346.

Taurog, A. and Dorris, M.L. (1989): A reexamination of the proposed inactivation of thyroid peroxidase in the rat thyroid by propylthiouracil. Endocrinology, 124, 3038-3042.

Yamada, T., Hasegawa, R., Nishikawa, S., Sakuratani, Y., Yamada, J., Yamashita, T., Yoshinari, K., Yamazoe, Y., Kamata, E., Ono, A., Hirose, A. and Hayashi, M. (2013): A new parameter that supports speculation on the possible mechanism of hypothyroidism induced by chemical substances in repeated-dose toxicity studies. J. Toxicol. Sci., 38, 291-299.

Yamasaki, K., Tago, Y., Nagai, K., Sawaki, M., Noda, S. and Takatsuki, M. (2002): Comparison of toxicity studies based on the draft protocol for the 'Enhanced OECD Test Guideline no. 407 ' and the research protocol of 'Pubertal Development and Thyroid Function in Immature Male Rats' with 6-n-propyl-2thiouracil. Arch. Toxicol., 76, 495-501. 